\title{
Correlation of Foot Bimalleolar Angle with Pirani Scoring System in Clinical Evaluation of Congenital Talipes Equinovarus
}

\author{
${ }^{1}$ Abhay Shankar Dube, ${ }^{2}$ Manvender Gaur, ${ }^{3}$ Avinash Rastogi, ${ }^{4}$ Rajat Kapoor
}

\begin{abstract}
The correlation of anteromedial foot bimalleolar angle with Pirani score evaluated prospectively in 120 children (204 feet) with congenital talipes equinovarus (CTEV). The patients were divided into groups I, II and III based on clinical severity before casting, having the Pirani score 0 to $2,2.5$ to 4 and 4.5 to 6 respectively. Mean foot bimalleolar angle $75.75^{\circ}, 67.62^{\circ}$ and $58.28^{\circ}$ of groups I, II and III respectively was correlated by standard deviation with their Pirani scores to evaluate the severity difference among the groups before initiation of the casting treatment. The change in clinical severity or Pirani score was further correlated with the change in mean foot bimalleolar angle at the time of completion of casting and before bracing. The foot bimalleolar angle is an objective, quantitative and reproducible method which can be used to classify, prognosticate and to monitor the progress of the treatment.
\end{abstract}

Background: The prospective observational study on role of foot bimalleolar angle against the Pirani scoring in clinical evaluation of club foot in 120 children (204 feet) with mean age of 5.4 months treated by Ponseti technique of casting.

Keywords: Congenital talipes equinovarus, Foot bimalleolar angle, Pirani scoring and Podogram.

How to cite this article: Dube AS, Gaur M, Rastogi A, Kapoor R. Correlation of Foot Bimalleolar Angle with Pirani Scoring System in Clinical Evaluation of Congenital Talipes Equinovarus. J Foot Ankle Surg (Asia-Pacific) 2015;2(1):17-21.

Source of support: Nil

Conflict of interest: None

\section{INTRODUCTION}

Congenital talipes equinovarus (CTEV) or club foot is a multidirectional complex foot deformity. ${ }^{13}$ Idiopathic $\mathrm{CTEV}$ is one of the commonest foot deformity seen by orthopedic surgeons. ${ }^{6}$

The true etiology of club foot is unknown. The three basic components of club foot are equinus, varus and adduction deformities which present with tibial intorsion deformity. Equinus occurs at tibiotalar joint, inversion at subtalar joint and adduction mainly at mid-tarsal joint

\footnotetext{
${ }^{1} \mathrm{Head},{ }^{2,3}$ Assistant Professor, ${ }^{4}$ Junior Resident

${ }^{1-4}$ Department of Orthopedics, Chhatrapati Shivaji Subharti Medical College, Meerut, Uttar Pradesh, India
}

Corresponding Author: Abhay Shankar Dube, Head Department of Orthopedics, Chhatrapati Shivaji Subharti Medical College, Meerut, Uttar Pradesh, India, Phone: 09897069829, e-mail: abhaysdube@gmail.com (talonavicular and calcaneocuboid joint). The other associated secondary deformities can be cavus and clawing of toes. ${ }^{13}$

The goal of treatment of club foot is to correct all components of the deformity, to obtain a normal looking, functional, plantigrade, painless, supple foot.

Evaluation of idiopathic club foot is essential to assess the initial severity of deformity, to monitor the progress of treatment, to prognosticate and to identify early relapse. Before the evolution of scoring systems Ponseti and Smoley, ${ }_{19}$ Catterall, ${ }^{1}$ Dimeglio et $\mathrm{al}^{5}$ Harrold and Walker ${ }^{9}$ and Pirani scoring system ${ }^{19}$ there has been little objectivity in assessing the severity of the various components of the deformities. Kumar ${ }^{14}$ and Mckay ${ }^{15,16}$ took prints of plantar surface of feet to depict the correction. Among the several clinical scoring systems described by Ponseti IV and Smoley, ${ }^{19}$ Catterall, ${ }^{1}$ Dimeglio et al, ${ }^{5}$ Harrold and Walker. ${ }^{9}$ The Pirani scoring ${ }^{18}$ system which incorporates three components in hindfoot and three in midfoot, has gained popular acceptance. The hindfoot contracture score and midfoot contracture score were calculated to define the correction in each component. This system has been found to be user-friendly, reliable and predictable. It predicts the number of cast required to correct the deformity and the probability of Achilles tendon tenotomy. ${ }^{8,7}$ There are several scoring systems to accesses the severity of club foot such as in Catterall scoring ${ }^{1}$ four parameters were used depending upon deformity which was classified as 'resolving', by tendon or joint contracture and 'false correction'. Harrold and Walker ${ }^{9}$ classified club foot into three parameters according to deformity, whether foot could be held at or beyond neutral position (grade I), fixed equinus $<20^{\circ}$ (grade II) and $>20^{\circ}$ (grade III). Dimeglio scoring system ${ }^{5}$ foot was based on four major and four minor parameters, such as measuring the angles of equinus in sagittal plane, varus deviation in frontal plane, derotation around talus calcaneo-forefoot block, adduction of the forefoot on hindfoot in horizontal plane. According to scores, the foot was classified into four types 'benign', 'moderate', 'severe' and 'very severe'. Ponseti and Smoley ${ }^{19}$ classified foot according to ankle dorsiflexion, heel varus, forefoot supination and tibial torsion.

Despite the use of these scoring systems as assessment tools, the 'gold standard' remains to be established. 
Footprints and podographic foot bimalleolar angle as suggested by Jain et $\mathrm{al}^{11}$ is now being increasingly recognized as an assessment and prognostic tool for objective assessment of club foot although its supremacy or equivalence with scoring systems is yet to be established. In view of poor predictability of the present scoring systems and imaging, this study was conducted to find the correlation of foot bimalleolar angle with Pirani scoring system. ${ }^{7}$

\section{MATERIALS AND METHODS}

A total of 120 children with 204 feet were included in the study with mean age of 5.4 months. Six patients lost to follow-up were prospectively observed between the period of July, 2011 and August, 2014.

All children underwent treatment by Ponseti's technique of casting with or without Achilles tendon tenotomy. The children older than 18 months, syndromic club foot , CTEV previously treated by soft tissue release and children with associated lower limb anomalies affecting casting or scoring were excluded. The foot of the child was examined clinically by three surgeons who also verified the podograms on which the foot bimalleolar angle was calculated according to method described by Jain et $\mathrm{al}^{11}$ and Jain et al. ${ }^{12}$ The foot was kept plantigrade over white plain sheet on hard base held by an assistant from upper leg. The tips of malleoli were marked on the sheet by dropping pencil on the paper perpendicular by palpating the malleolar tip one by one. First line was drawn from the most convex part of the heel to the center of second toe. Second line was drawn from the mark of medial malleolus to the mark of lateral malleolus on the paper. The anteromedial angle at intersection was taken as foot bimalleolar angle. The podograms recorded with hazy or doubled sole imprint were discarded. The average/mean of three readings of foot bimalleolar angles was calculated to decrease the interobserver variation. The feet were graded according to their severity score by modifying the grading used by Jain et $\mathrm{al}^{11}$ as depicted in (Table 1). The fully corrected foot was considered to have normalized to 0 Pirani score before bracing. The normal foot bimalleolar angle was considered to be $82.5^{\circ}$ as observed by Jain et al. ${ }^{12}$

The severity difference among the three groups was evaluated by the calculating the difference in the mean foot bimalleolar angle of the three groups. The statistical significance of the severity difference was evaluated by using one-way ANOVA test.

Table 1: Three severity groups based on Pirani score

\begin{tabular}{ll}
\hline Groups according to Pirani score & Pirani scores \\
\hline Group I & $0-2$ \\
Group II & $2.5-4$ \\
Group III & $4.5-6$ \\
\hline
\end{tabular}

Post hoc ANOVA test applied to quantify the severity difference in foot bimalleolar angles among three groups.

\section{CLINICAL PHOTOGRAPH OF CHILD IN GROUP III}

The foot of children was examined clinically both by Pirani scoring and Podographic foot bimalleolar angle was drawn as shown (Fig. 1) at the time of preplaster, at time of tenotomy (Fig. 2) and at time of completion of treatment (Fig. 3).

\section{OBSERVATION AND RESULT}

The mean foot bimalleolar angle 36 feet in preplaster group I was $75.75^{\circ}\left(70-84^{\circ}\right.$; SD 4.309), foot bimalleolar angle for 72 feet in group II was $67.62^{\circ}\left(59-76^{\circ}\right.$; SD 5.815) and foot bimalleolar angle for 96 feet in group III was $58.28^{\circ}\left(51-69^{\circ}\right.$; SD 7.086) (Table 2). All these three groups were found to have statistical significant difference $(\mathrm{p}<0.01)$ by using one-way ANOVA test (Table 3).

Post hoc ANOVA test was applied to quantify the difference in severity among the three groups. The quantitative difference between the means of foot bimalleolar angle in group I with groups II and III was statistically significant and so among the groups II and III (Table 4).

The correlation of foot bimalleolar angle and clinical severity was prospectively evaluated in this study. The percentage change in foot bimalleolar angle of three groups was found to match with the percentage change in Pirani score at the time of tenotomy and before bracing.

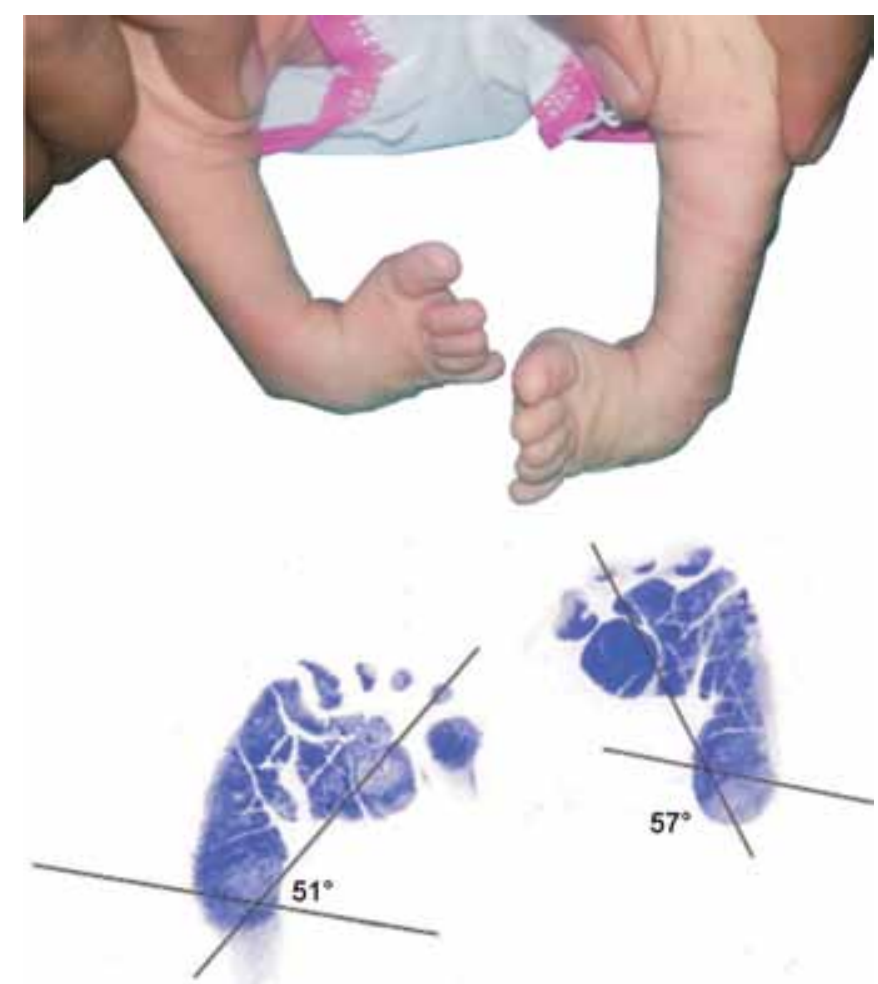

Fig. 1: Clinical photograph before initiation of treatment. Pirani's score: 5.5 of both feet; FBM angle $51^{\circ}$ on left side and $57^{\circ}$ on right side 


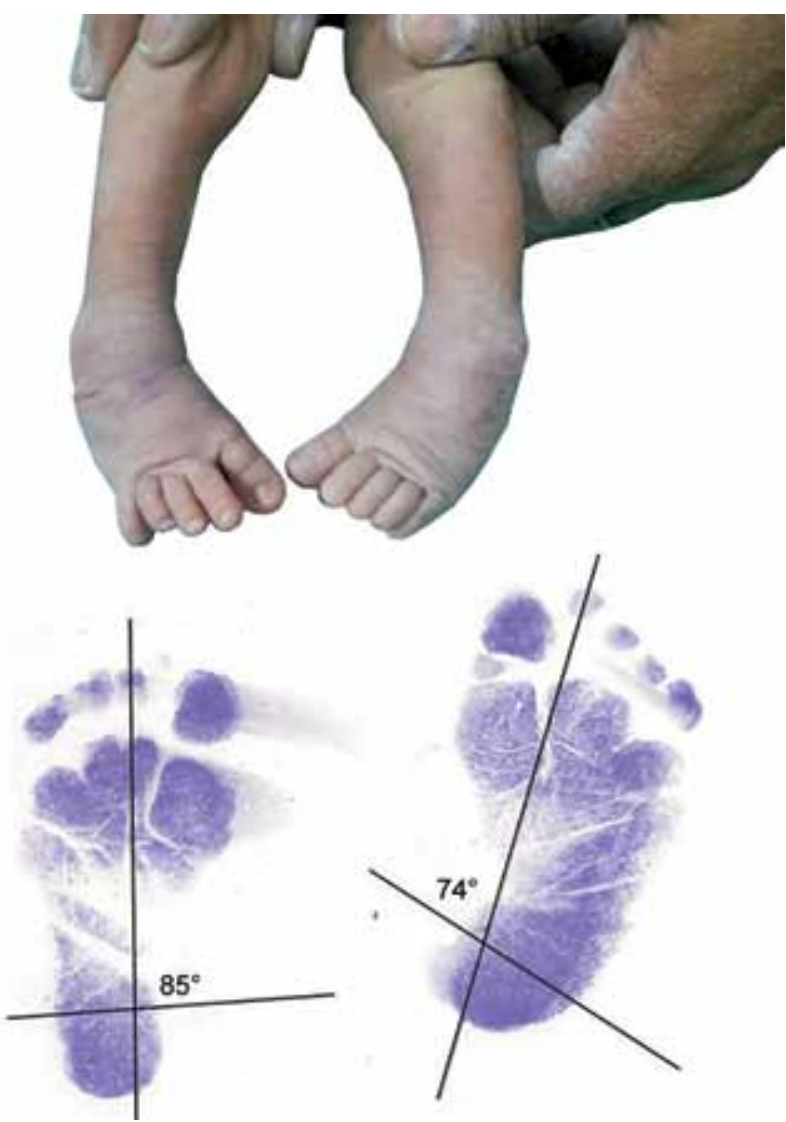

Fig. 2: Clinical photograph and podogram at the time of tenotomy. Pirani's score: 0.5 on left side; 1.5 on right side. FBM $85^{\circ}$ on right side and $74^{\circ}$ on left side
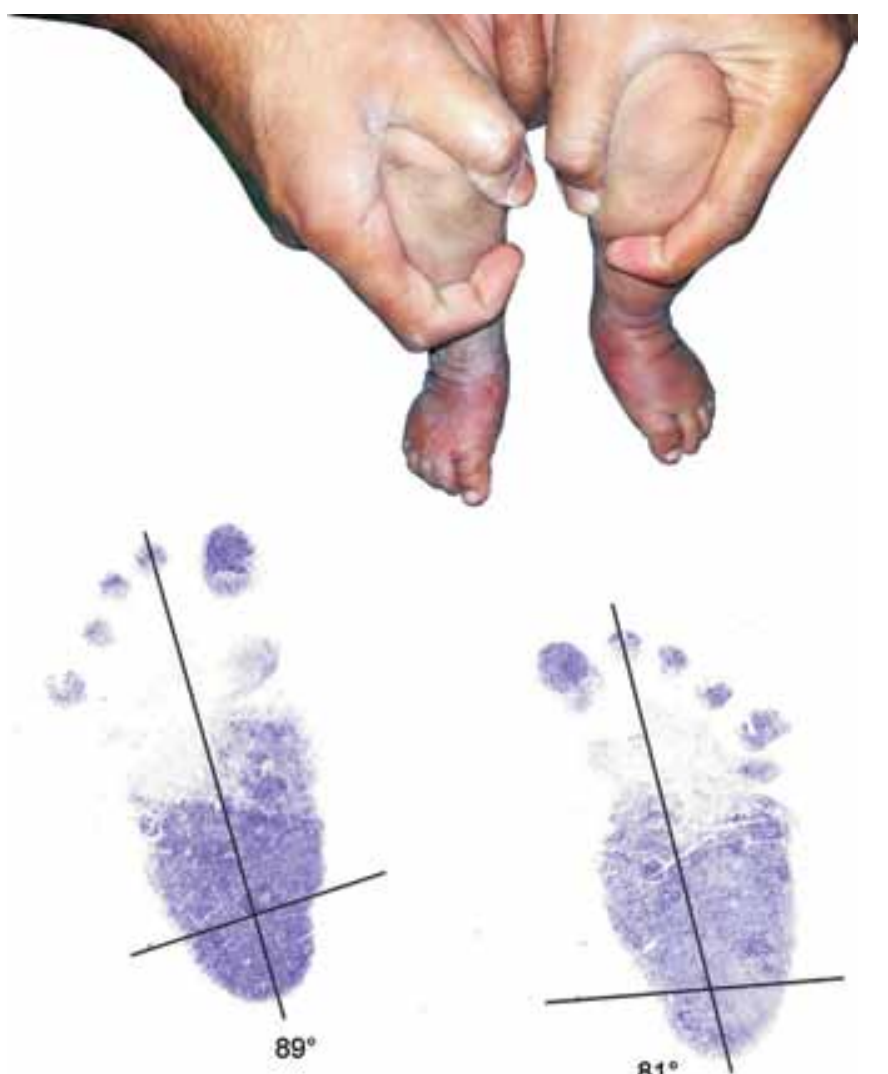

Fig. 3: Clinical photograph and podogram at the time of completion of the treatment. Pirani's score: zero on both side. FBM $89^{\circ}$ on left side and $81^{\circ}$ on right side
(Table 5). The average FBM and Pirani score of the three groups reached the same change at the time of completion of the treatment. The improvement in the average foot bimalleolar angle of the three groups preceded the improvement of the Pirani's score but both plateau at the time of completion of the treatment, i.e. at the time of bracing.

\section{DISCUSSION}

Idiopathic club foot is a complex foot deformity that is difficult to correct. The goal of the treatment is to achieve a supple, pain free, plantigrade foot with good function, with healing of callosity which will not need any special foot orthosis after maturity. When starting a treatment it is important to describe the treatment to the parents and predict with reasonable accuracy the outcome of the treatment. Club foot is a condition which is variable both in severity and its expected response to the treatment which leads to unpredictability in the duration and type of the treatment required.

The factors that challenge the management of this condition, apart from the deformity itself, are the variations in the description of the observed deformities by various scoring systems. The need is felt by all foot surgeons to develop a method of assessment which is not only easy to learn and apply but is also reproducible

Table 2: Preplaster mean foot bimalleolar angle and standard deviation in three groups

\begin{tabular}{lll}
\hline $\begin{array}{l}\text { Groups according to } \\
\text { Pirani scoring }\end{array}$ & $\begin{array}{l}\text { Mean foot bimalleolar } \\
\text { angle and SD }\end{array}$ & $\begin{array}{l}\text { Std. error } \\
\text { of mean }\end{array}$ \\
\hline Group I (0-2) & $75.75^{\circ}\left(70-84^{\circ}\right)$, & \\
$\mathrm{n}=36$ & 4.309 & 1.244 \\
Group II (2.5-4) & $67.62^{\circ}\left(59-76^{\circ}\right)$, & \\
$\mathrm{n}=72$ & 5.815 & 1.187 \\
Group III (4.5-6) & $58.28^{\circ}\left(51-69^{\circ}\right)$, & \\
$\mathrm{n}=96$ & 7.086 & 1.253 \\
\hline SD: Standard deviation & &
\end{tabular}

SD: Standard deviation

Table 3: Mean difference in preplaster foot bimalleolar angles in three groups

\begin{tabular}{|c|c|c|c|c|c|}
\hline Groups & $\begin{array}{l}\text { Sum of } \\
\text { square }\end{array}$ & Difference & $\begin{array}{l}\text { Mean } \\
\text { square }\end{array}$ & F-ratio & $p<0.01$ \\
\hline $\begin{array}{l}\text { Between } \\
\text { groups }\end{array}$ & 2988.877 & 2 & 1494.438 & 38.268 & $<0.01$ \\
\hline $\begin{array}{l}\text { Within } \\
\text { groups }\end{array}$ & 2538.344 & 65 & 39.051 & & \\
\hline Total & 5527.221 & 67 & & & \\
\hline
\end{tabular}

Table 4: Mean difference between preplaster foot bimalleolar angles in three groups

\begin{tabular}{ll}
\hline Groups & Mean difference between groups $(p<0.01)$ \\
\hline I and II & $8.125(<0.01)$ \\
II and III & $9.344(<0.01)$ \\
III and I & $17.469(<0.01)$ \\
\hline
\end{tabular}


Table 5: Improvement in Pirani score and foot bimalleolar angle with casting

\begin{tabular}{|c|c|c|c|c|}
\hline \multirow[b]{2}{*}{ Groups } & \multirow{2}{*}{$\begin{array}{l}\text { Average Pirani score, foot bimalleolar angle and } \\
\text { percentage change }\end{array}$} & \multirow[b]{2}{*}{ Preplaster } & \multicolumn{2}{|c|}{ Severity change } \\
\hline & & & Before tenotomy & Before bracing \\
\hline \multirow[t]{6}{*}{$I(n=36)(0-2)$} & Average Pirani score & 2 & 1.37 & 0 \\
\hline & Percentage severity & $33.33 \%$ & $22.92 \%$ & $0 \%$ \\
\hline & Percentage change & & $10.41 \%$ & $22.92 \%$ \\
\hline & Average foot bimalleolar angle & $75.75^{\circ}$ & $80.67^{\circ}$ & $82.5^{\circ}$ \\
\hline & Percentage improvement & $91.82 \%$ & $97.7 \%$ & $100 \%$ \\
\hline & Percentage change & & $5.88 \%$ & $2.3 \%$ \\
\hline \multirow[t]{6}{*}{ II $(n=72)(2.5-4)$} & Average Pirani score & 3.6 & 1.4 & 0.041 \\
\hline & Percentage severity & $61.45 \%$ & $23.83 \%$ & $0.68 \%$ \\
\hline & Percentage change & & $37.62 \%$ & $23.14 \%$ \\
\hline & Average foot bimalleolar angle & $67.62^{\circ}$ & $76.08^{\circ}$ & $82^{\circ}$ \\
\hline & Percentage improvement & $81.96 \%$ & $92.21 \%$ & $99.39 \%$ \\
\hline & Percentage change & & $10.25 \%$ & $7.18 \%$ \\
\hline \multirow[t]{6}{*}{ III $(n=96)(4.5-6)$} & Average Pirani score & 4.02 & 3.15 & 0.34 \\
\hline & Percentage severity & $66.92 \%$ & $52.50 \%$ & $5.72 \%$ \\
\hline & Percentage change & & $14.42 \%$ & $46.78 \%$ \\
\hline & Average foot bimalleolar angle & $58.28^{\circ}$ & $71.71^{\circ}$ & $79.12^{\circ}$ \\
\hline & Percentage improvement & $70.64 \%$ & $86.90 \%$ & $95.98 \%$ \\
\hline & Percentage change & & $16.26 \%$ & $9.08 \%$ \\
\hline
\end{tabular}

in multiple hands and has objectivity in assessing the response to the treatment. The ideal grading system for club foot on a severity scale should be ideally applicable to all form of CTEV and should not be affected by age of the child so that it can provide objective recoverable data for a retrospective analysis.

The observations by Wynne-Davies ${ }^{22}$ Cohen-Sobel et $\mathrm{al}_{1}{ }^{2}$ Mckay ${ }^{15-17}$ found that most patients had excellent levels of function despite having anatomically and radiographically imperfect feet have reinforced this disparity. The studies by Thompson et $\mathrm{al}^{21}$ and Cohen-Sobel et $\mathrm{al}^{2}$ further supported this dilemma. Herbsthofer et $\mathrm{al}^{10}$ emphasized that clinical evaluation should be the yardstick against which any other method can be compared.

Wainwright et $\mathrm{al}^{23}$ established that the clinical method suggested by Dimeglio et $\mathrm{al}^{5}$ is more reliable than method suggested by Ponseti and Smoley ${ }^{19}$ Catterall ${ }^{1}$ and Harrold and Walker. ${ }^{9}$ The use of foot prints or foot tracings has been described in the orthopedic literature Kumar, ${ }^{14}$ Cummings et $\mathrm{al}^{3}$ Jain et $\mathrm{al}_{1}{ }^{12}$ Simons ${ }^{20}$ McKay. ${ }^{15-17}$ The method suggested by Dimeglio et a ${ }^{5}$ has both subjective and objective values. Pirani score objectifies the hindfoot and midfoot contracture scores which are responsible for the appearance of the forefoot in club foot deformity.

The relation of calcaneal axis with bimalleolar plane, described by Cummings et al ${ }^{4}$ by CT scan motivated the description of podographic foot bimalleolar angle by Jain et $\mathrm{al}^{11}$ as an angle between bimalleolar line and the longitudinal foot axis which depended on the shape of the heel and the position of the forefoot. It is a combined indirect indicator of forefoot adduction and the hindfoot varus which are the main components of the club foot deformity and this corresponds anatomically to the amount of calcaneal rotation beneath the talus. The improvement in the shape of the heel and forefoot corresponds to the change in the foot bimalleolar angle and correction of the calcaneal rotation which is the basic pathoanatomical abnormality in club foot as proved by Ponseti and Smoley. ${ }^{19}$

Jain et $\mathrm{al}^{12}$ studied the foot bimalleolar angle in normal infants and concluded that this angle is simple, objective and reproducible criterion to classify the severity of foot deformity and to evaluate the results of treatment. They found the average $\mathrm{FBM}$ to be $82.5^{\circ}$ in the normal population. In patients with idiopathic CTEV they found the average FBM to be 73.2, 66.6 and 54.7 degree in Grade I, II and III respectively based on the Kite's method of treatment. They also observed a correlation of foot bimalleolar angle with the outcome of the treatment. This supported the fact that foot bimalleolar angle improves with the correction of the alignment of hindfoot with the forefoot irrespective of the method used for correction and reported a failure rate of $56 \%$ in grade III feet. They, however, used a very subjective method to grade the outcome of their results which is not universally acceptable.

Jain et $\mathrm{al}^{11}$ did a point study and classified the feet into three groups, based on the Pirani severity score. The maximum Pirani score was 2, 4 and 6 of groups I, II and III respectively. They used more objective criteria as compared to clinical grading criteria used by Jain et al. ${ }^{12}$ They analyzed the patients in the pretreatment stage and established an indirect correlation between the clinical severity grading and average foot bimalleolar angle. They reported a statistical significant difference in the means of 
foot bimalleolar angles of groups I, II and III among each other but did not study a relation between the change in FBM and clinical correction with the course of the treatment. This forms the basis of the present study.

The Pirani scoring system has been the most widely used clinical system so in this study, groups were divided on the basis of the severity denoted by Pirani score. The three groups made on the basis of severity of the Pirani's score were found to have average FBM of $75.75^{\circ}, 67.62^{\circ}$ and $58.28^{\circ}$ in groups I, II and III respectively, which are comparable to the studies done previously by Jain et $\mathrm{a}^{12}$ and Jain et al. ${ }^{11}$ The three groups found to have overlapping values of foot bimalleolar angle as also noticed by Jain et al. ${ }^{11}$

In our study, the relation of foot bimalleolar angle and clinical severity by Pirani score was analysed at three specific times-before the initiation of the treatment, at the time of tenotomy and before bracing. Jain et $\mathrm{al}^{11}$ found no significant difference between the severities of average foot bimalleolar angle with Pirani severity score emphasizing indirectly that the foot bimalleolar angle has a direct relation with the clinical severity. During prospective follow-up of children undergoing casting in this study, it was observed that the percentage change of Foot bimalleolar angle and Pirani score, evaluated at two instances at the time of tenotomy and before bracing, is similar and comparable to each (Table 5). In all the feet grouped according to severity Jain et $\mathrm{l}^{11}$ both Pirani score and average foot bimalleolar angle reached their normal or near normal value during cast correction. It can be discerned from this fact that foot bimalleolar angle not only has direct objective relation with the clinical severity but also a marker of the degree of correction achieved $(\mathrm{p}=0.01)$ (Table 3).

In this study, we found that Podographic foot bimalleolar angle provide objective evidence of correction of deformities of idiopathic club foot which can be easily documented without affecting hospital resources. The implication of this interesting observation is that when measured sequentially, podographic foot bimalleolar angle can give indirect objective evidence whether the deformities were getting corrected or not so that surgery could be recommended. Whether podographic foot bimalleolar angle measurement would equally be useful in evaluating feet undergoing posteromedial soft tissue release or not requires to be validated by further study. Several studies have shown that many scoring systems in current use lack adequate interobserver and intraobserver consistency. Pirani scoring after Ponseti casting has the maximum impact factor due to its simplicity in orthopedic practice and is most widely used for the assessment of deformity and comparison of the results.

\section{REFERENCES}

1. Catterall A. A method of assessment of the club foot deformity. Clin Orthop Related Res 1991;264:48-53.

2. Cohen-Sobel E, Caselli M, Giorgini R, Giorgini T, Stummer S. Long-term follow-up of club foot surgery: analysis of 44 patients. J Foot Surg 1993;32(4):411-423.

3. Cummings RJ, Lovell WW. Operative treatment of congenital club foot. J Bone Joint Surg Am 1988;70(7):1108-1112.

4. Cummings RJ, Deese M, Bradshaw J. The circumferential club foot release: does it accomplish what it is intended to? Orthop Trans 1987;11:444.

5. Dimeglio A, Bensahel H, SouchetP, Mazeau P, Bonnet F. Classification of club foot . J Pediatric Orthop B 1995;4(2):129-136.

6. Dobbs MB, Morcuende JA, Gurnett CA, Ponseti IV. Treatment of idiopathic club foot. Iowa J Orthop 2000;20:59-64.

7. Dyer PJ, Davis N. The role of pirani scoring system in management of club foot by ponseti method. J Bone Joint Surg Br 2006;88(8):1082-1084.

8. Goriainov V, Jud J, Uglow M. Does pirani score predict relapse in club foot? J Child Orthop 2010;4(5):439-444.

9. Harrold AJ, Walker CJ. Treatment and prognosis in congenital club foot . J Bone Joint Surg (Br) 1983;65-B(1):8-11.

10 Herbsthofer B, Eckardt A, RompeJD, Kullmer K. Significance of radiographic angle measurements in evaluation of congenital club foot . Arch Orthop Trauma Surg 1998;117(6-7):324-329.

11. Jain P, Mehtani A, Goel M, Jain S, Sood A, Jain AK. Correlation of foot bimalleolar angle with Pirani score to assess the severity of congenital talipes equino varus. J Pediatric Orthop B 2012;21(1):68-72.

12. Jain AK, Zulfikar AM, Kumar S, Dhammi IK. Evaluation of foot bimalleolar angle in congenital talipes equino varus. J Pediatric Orthop 2001;21(1):55-59.

13. Kelly DM. Congenital anomalies of lower extremity. In: campbell's operative orthop. Canale ST, Beaty JH. 12th ed. St Louis: Mosby Elsevier 2008. p. 1079-1100.

14. Kumar K. The role of footprints in management of clubfeet. Clin Orthop Related Res 1979 May;140:32-36.

15. Mckay DW. New concept and approach to club foot treatment. Section II-Correction of club foot . J Pediatric Orthop 1983;3(1):10-21.

16. Mckay DW. New concept and approach to club foot treatment. Section III-correction of club foot . J Pediatric Orthop 1983;3(2): 141-148.

17. Mckay DW. New concept of approach in club foot treatment. Section I-principles and morbid anatomy. J Pediatric Orthop 1982;2(4):347-356.

18. Pirani S, Outerbridge HK, Sawatzky B, Stothers K. A reliable method of clinically evaluating a virgin club foot evaluation. 21st World Congress of SICOT 1999.

19. Ponseti IV, Smoley EN. Congenital club foot . J Bone Joint Surg (Am) 1963;45(2):261-344.

20. Simon GW. Complete subtalar release in club feet Part IIcomparison with less extensive procedures. J Bone Joint Surg (Am) 1985 Sep;67(7):1056-1065.

21. Thompson GH, Richardson AB, Westin GW. Surgical management of resistant congenital talipes equinovarus deformities. J Bone Joint Surg (Am) 1982 Jun;64(5):652-665.

22. Wynne-Davies R. Family study and the cause of congenital club foot. J Bone Joint Surg 1964;46-B(3):445-462.

23. Wainwright AM, Auld T, Benson MK, Theologis TN. The classification of congenital talipes equinovarus. J Bone Joint Surg (Br) 2002;84(7):1020-1024. 